\title{
Statins for the primary prevention of cardiovascular disease
}

\author{
Shah Ebrahim professor of public health and policy ${ }^{1}$, Fiona C Taylor managing editor, Cochrane \\ Heart Group ${ }^{1}$, Peter Brindle general practitioner ${ }^{2}$
}

${ }^{1}$ Department of Non-communicable Disease Epidemiology, London School of Hygiene and Tropical Health, London WC1E 7HT, UK; ${ }^{2}$ Avon Primary Care Research Collaborative, Bristol Clinical Commissioning Group, Bristol BS1 3NX, UK

This is one of a series of occasional articles on therapeutics for common or serious conditions, covering new drugs and old drugs with important new indications or concerns. The series advisers are Robin Ferner, honorary professor of clinical pharmacology, University of Birmingham and Birmingham City Hospital, and Albert Ferro, professor of cardiovascular clinical pharmacology, King's College London. To suggest a topic for this series, please email us at practice@bmj.com.

A 55 year old former financial services manager attended a cardiovascular risk check, which showed he had a $15 \%$ risk of suffering a major cardiovascular event in the next 10 years. ${ }^{1} \mathrm{He}$ asks his general practitioner whether he needs a statin given his risk. His risk factors are being overweight; moderate smoker; blood pressure 150/90 $\mathrm{mm} \mathrm{Hg}$; and serum total cholesterol concentration $5.5 \mathrm{mmol} / \mathrm{L}$, high density lipoprotein cholesterol $1.2 \mathrm{mmol} / \mathrm{L}$, low density lipoprotein cholesterol $3.5 \mathrm{mmol} / \mathrm{L}$, triglycerides $1.7 \mathrm{mmol} / \mathrm{L}$.

\section{What are statins?}

Statins inhibit 3-hydroxy-3-methylglutaryl coenzyme A (HMG-CoA) reductase, involved in cholesterol biosynthesis. Low density lipoprotein (LDL) cholesterol concentration is lowered by reducing its production in the liver and increasing removal from the circulation. ${ }^{2}$ Lowering blood levels of LDL cholesterol, a major risk factor for cardiovascular disease, reduces the chances of having cardiovascular disease. Statins also have anti-inflammatory effects, improve endothelial function, and reduce thrombus formation, but these effects may not be independent of cholesterol lowering or reduce cardiovascular disease risk. ${ }^{3}$ Expert committees promote their use on a global scale, ${ }^{4-7}$ and statin prescribing and expenditure have risen rapidly. In England, prescriptions for statins rose fivefold from 2001 to 2011 to $£ 61 \mathrm{~m}$ a year ( $£ 544$ average annual cost per person). ${ }^{8}$

\section{How well do they work?}

Statins are indicated for secondary prevention of cardiovascular disease. The Cholesterol Treatment Trialists Collaboration reviewed data from 27 clinical trials of statins (170 000 participants) for both primary and secondary prevention and reported a $20 \%$ relative risk reduction per $1 \mathrm{mmol} / \mathrm{L}$ reduction in LDL cholesterol concentration for major vascular events. These beneficial effects were seen in both men and women, at ages from $<60$ to $>70$ years, in people with and without cardiovascular disease, in those at high and low cardiovascular disease risk, in diabetics, and in those with average levels of blood cholesterol. ${ }^{9}$

A Cochrane systematic review of statins for primary prevention of cardiovascular disease included 18 trials (56934 participants, most with one or more cardiovascular disease risk factor).$^{10} \mathrm{It}$ found that statins lowered cardiovascular disease risk by $27 \%$ (table $\downarrow$ ). The median level of cardiovascular disease risk observed in the control groups of the trials was equivalent to $15 \%$ over 10 years (the same as the current case). Over five years, the number needed to treat $\left(\mathrm{NNT}_{5}\right)$ to avoid one cardiovascular event was 50 . The $\mathrm{NNT}_{5}$ for people at $10 \%, 20 \%$, and $30 \%$ predicted cardiovascular event risk over 10 years were 74,37 , and 25 respectively. These compare with $\mathrm{NNT}_{5}$ values of between 12 and 34 in secondary prevention.

\section{How safe are they?}

Use of statins by low risk patients has been criticised on the grounds that their benefits do not outweigh their harms ${ }^{12}$ and debated. ${ }^{13}{ }^{14}$ However, all cause mortality in people taking statins with no pre-existing cardiovascular disease is reduced (table $\downarrow$ ), indicating that any unintended life threatening effects are outweighed by their beneficial impact on cardiovascular disease, although this evidence is not strong. ${ }^{15}$ Earlier concerns about cancer risk are unfounded. ${ }^{16}$ However, other unintended effects 
are not comprehensively reported in systematic reviews or trials. $^{17}$

Adverse events and stopping treatment because of them are common, but occur at similar rates in treated and control groups in clinical trials (17\% and $12 \%$ respectively), ${ }^{10}$ making it difficult to ascribe these events to statins. Reports of reduced energy, fatigue, depressed mood, and reduced quality of life show inconsistent findings. ${ }^{18-20}$ Myositis ( $\mathrm{a} \geq 10$-fold rise in normal levels of creatine kinase) is caused by statins, but myalgia (muscle pain without raised creatine kinase) is not linked with statin use. ${ }^{21}$ In two large, well conducted, observational analyses using national primary care datasets, the numbers needed to harm for incident myositis associated with five years of statin treatment were between $90^{22}$ and $250 .{ }^{23}$ Rhabdomyolysis-an extreme form of myositis that can be serious if not detected and treated early-may be caused by statins but is very rare. ${ }^{24}$ Myositis and other adverse effects are more common with aggressive lowering of cholesterol levels by means of potent statins such as rosuvastatin or higher doses of statins (such as doubling of usual doses). ${ }^{25}$

Statins are associated with an increased risk of developing type 2 diabetes, ${ }^{1126}$ especially at higher doses. ${ }^{27}$ Only two primary prevention trials reported on type 2 diabetes outcomes, with a pooled relative risk of 1.18 (95\% confidence interval 1.01 to 1.39). This result is consistent with a larger meta-analysis that included both primary and secondary prevention trials, which found that treating 255 people for four years would cause one case of diabetes, but this would be offset by avoiding more than five major vascular events (table $\downarrow$ ). ${ }^{11}$ This increased risk of diabetes was related to baseline fasting glucose levels among trial participants. ${ }^{28}$

Haemorrhagic stroke was not increased by use of statins in a meta-analysis of randomised trials (odds ratio 1.08 (95\% confidence interval 0.88 to 1.32$)$ ) ${ }^{2}{ }^{2}$ Large observational primary care datasets found no strong evidence that statins were associated with an increased risk of Parkinson's disease, rheumatoid arthritis, venous thromboembolism, dementia, osteoporotic fracture, or infections, and confirmed the evidence from randomised trials of no increased risk of cancer. ${ }^{22}{ }^{23}$ Other possible adverse effects of statins (cataracts, depression, and peripheral neuropathy) and possible benefits (on bone mineral density, cognition, and macular degeneration) have not been confirmed in randomised trials. ${ }^{20}$

Patients may expect not to be harmed in any way by preventive treatment with statins, and their views of trade-offs between benefit and possible harms will likely determine the wider use of statins. ${ }^{30}$

\section{How are statins taken?}

The National Institute for Health and Care Excellence (NICE) guidelines recommend that, before starting a statin, all patients should have a comprehensive assessment of their cardiovascular risk factors and secondary causes of dyslipidaemia considered (see box 1). ${ }^{31}$ Patients should be advised to deal with modifiable risk factors before starting statins. Current NICE guidance uses a threshold of $\geq 20 \%$ for 10 year risk of cardiovascular disease for using statins. People at lower cardiovascular risk may also benefit, however, ${ }^{9}$ and the new American College of Cardiology/American Heart Association guideline has lowered its treatment threshold to a predicted $7.5 \%$ for 10 year cardiovascular risk. ${ }^{32}$

\section{What are the precautions?}

General contraindications to prescribing statins include women during pregnancy and breast-feeding, previous hypersensitivity reactions to a statin, active liver disease, renal failure, and heavy drinkers (50+ units a week). Both the USA and UK drug regulatory agencies have issued safety alerts advising blood glucose monitoring in patients at risk of developing diabetes and taking statins. ${ }^{33}$ However, based on current evidence, statins should not be avoided in patients with pre-existing diabetes who are at high risk of cardiovascular disease.

\section{Drug interactions}

Many drugs are metabolised by the cytochrome P450 isoenzyme system, which also metabolises statins, and consequently drug-drug interactions may occur. ${ }^{35}$ Patients with renal disease, HIV infection, and organ transplants are more prone to interactions. A wide range of drugs have been implicated in interactions. Patients treated with these drugs should be monitored for possible side effects, such as muscle pain and gastrointestinal symptoms (see box 2). Patients taking simvastatin should be advised to avoid drinking grapefruit juice. Lower doses of statins are less likely to provoke clinically important interactions.

\section{How cost effective are statins?}

For primary prevention of cardiovascular disease, cost per QALY is variable depending on the level of cardiovascular disease risk, age, and cost of statins, with NICE supporting their use in people with predicted 10 year cardiovascular risk of $>20 \%$. $^{6}$ The costs per QALY were based on NHS costs in 2004 when most statins were still in patent. These estimates need updating given the large reductions in their costs.

\section{How do statins compare with other drugs and interventions?}

Statins are not the only means of reducing risk of cardiovascular disease. People at high cardiovascular risk can reduce their risk by making lifestyle changes (see figure $\Downarrow$ and case outcome).

If a statin is not tolerated, switching to an alternative statin and starting at a low dose may work. Fibrates (bezafibrate, ciprofibrate, fenofibrate, gemfibrozil) lower cholesterol, but evidence of clinical effectiveness is limited. NICE recommends use of ezetimibe when statins are contra-indicated or not tolerated, or in conjunction with a statin when LDL cholesterol concentration is not controlled by optimal statin therapy. ${ }^{31}$ Combination statin and fibrate treatment may be used when blood triglyceride levels are raised and are not controlled with a statin alone. However, evidence of clinical benefits from combination treatment is limited and side effects (such as muscle pain) are common.

Nicotinic acid, plant sterols and stanols, anion exchange resins, and omega 3 fatty acid supplements are not recommended by NICE for cholesterol lowering in primary prevention.

\section{Case outcome}

Stopping smoking would reduce the patient's predicted 10 year cardiovascular disease risk from $15 \%$ to $11 \%$. If he takes a statin instead and gains the typical $1 \mathrm{mmol} / \mathrm{L}$ reduction in LDL cholesterol level, this too would reduce his predicted cardiovascular disease risk to $11 \%$ (see figure $\Downarrow$ ). Stopping smoking and taking a statin would reduce this further to $9 \%$ 

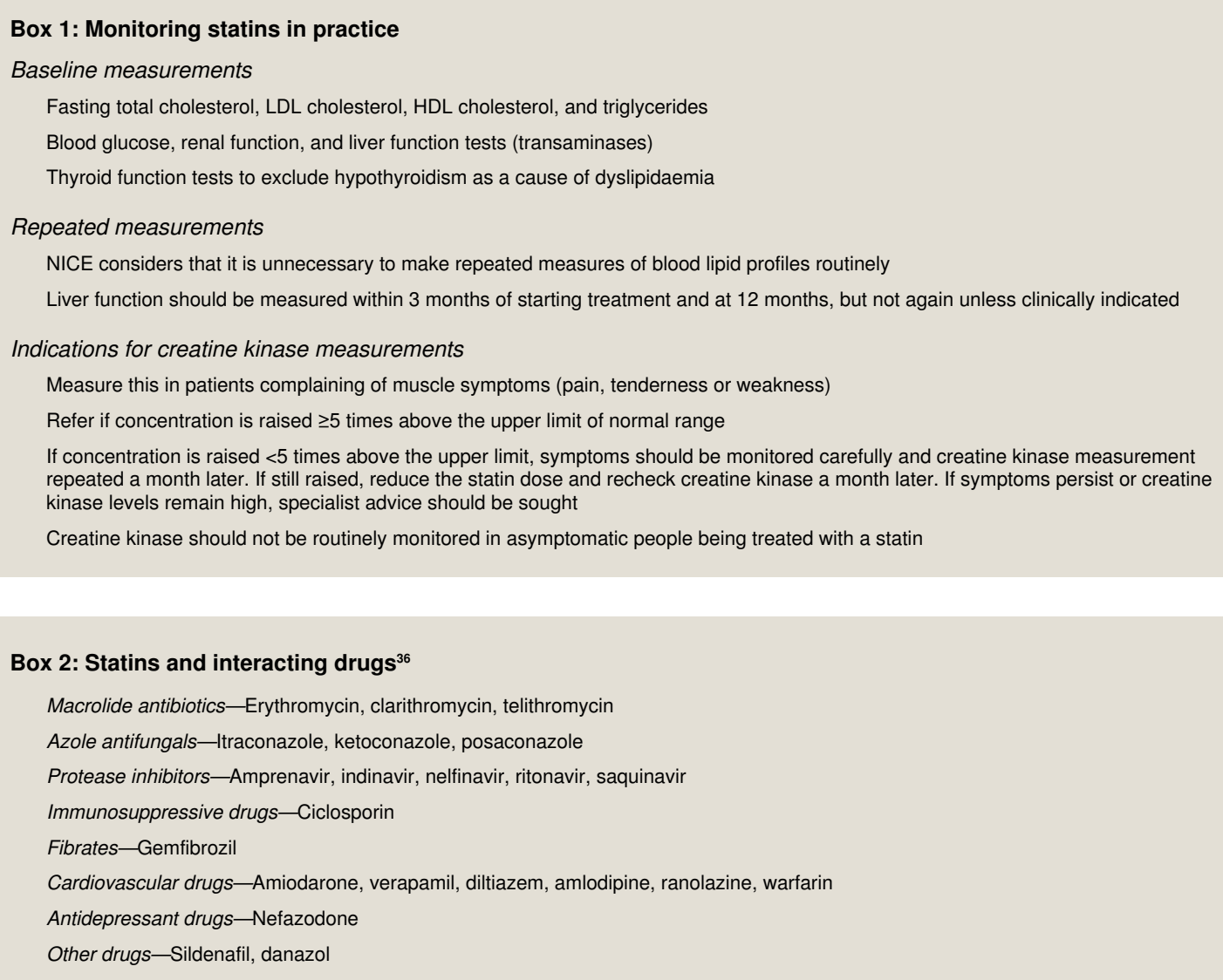

As he is overweight and hypertensive, a programme of alcohol reduction, increased physical activity, and attending a weight reduction course might achieve a lower blood pressure and would combat other cardiovascular risk factors not included in the risk score. Adding a statin to these lifestyle measures would, on average, almost halve his risk to $8 \%$ (assuming he does not revert to his adverse lifestyle as the statin is now "doing the job”) with an $\mathrm{NNT}_{5}$ of approximately 60 for cardiovascular disease events.

His predicted 10 year cardiovascular disease risk is lower than the NICE threshold of $\geq 20 \%$; treating him with a statin would go against current English guidance.

Contributors: FCT planned and wrote the first draft. SE interpreted the data and redrafted the manuscript where required. PB contributed to the drafting and revision of the manuscript. All authors gave final approval of the article. SE is responsible for the overall content and acts as guarantor.

Competing interests: We have read and understood the BMJ Group policy on declaration of interests and we have no relevant interests to declare. PB was involved in the development of QRISK.

Provenance and peer review: Commissioned; externally peer reviewed. Patient consent not required (patient anonymised, dead, or hypothetical).

1 QIntervention. QRISK. ClinRisk, University of Nottingham, 2012. http://qintervention.org/ index.php.

2 Wierzbicki AS, Poston R, Ferro A. The lipid and non-lipid effects of statins. Pharmacol Ther 2003;99:95-112

3 Bonetti P, Lerman L, Napoli C, Lerman A. Statin effects beyond lipid lowering-are they clinically relevant? Eur Heart $J$ 2003;24:225-48.

4 Genest J, McPherson R, Frohlich J, Anderson T, Campbell N, Carpentier A, et al. 2009 Canadian Cardiovascular Society/Canadian guidelines for the diagnosis and treatment of dyslipidemia and prevention of cardiovascular disease in the adult-2009 recommendations. Can J Cardiol 2009;25:567-79.

5 Manuel D, Kwong K, Tanuseputro P, Lim J, Mustard C, Anderson GM, et al. Effectiveness and efficiency of different guidelines on statin treatment for preventing deaths from coronary heart disease: modeling study. BMJ 2006;332:1419.
6 National Institute for Health and Care Excellence. Statins for the prevention of cardiovascular events in patients at increased risk of developing cardiovascular disease or those with established cardiovascular disease (Technology appraisal TA94). 2006. www.nice.org.uk/TA094.

7 European Association for Cardiovascular Prevention \& Rehabilitation, Reiner Z, Catapano AL, De Backer G, Graham I, Taskinen MR, et al. ESC/EAS guidelines for the management of dyslipidaemias. The Task Force on the management of dyslipidaemias of the European Society of Cardiology (ESC) and the European Atherosclerosis Society (EAS). Eur Heart Society of Cardiology

8 Prescriptions Dispensed in the Community: England, Statistics for 2001 to 2011. Health and Social Care Information Centre, 2011. https://catalogue.ic.nhs.uk/publications/ prescribing/primary/pres-disp-com-eng-2001-11/pres-disp-com-eng-2001-11-rep.pdf.

9 Cholesterol Treatment Trialists (CTT) Collaboration. The effects of lowering LDL cholesterolwith statin therapy in people at low risk of vascular disease: meta-analysis of individual data from 27 randomised trials. Lancet 2012;378:67-5.

10 Taylor F, Huffman MD, Macedo AF, Moore THM, Burke M, Davey Smith G, et al. Statins for the primary prevention of cardiovascular disease. Cochrane Database Syst Rev 2013;1:CD004816.

11 Sattar N, Preiss D, Murray HM, Welsh P, Buckley BM, de Craen AJ. Statins and risk of incident diabetes: a collaborative meta-analysis of randomised statin trials. Lancet 2010:375:735-42.

12 Abramson JD, Rosenberg HG, Jewell N, Wright JM. Should people at low risk of cardiovascular disease take a statin? BMJ 2013;347:f6123.

13 Huffman M, Taylor F, Ebrahim S. Should people at low risk of cardiovascular disease take a statin? www.bmj.com/content/347/bmj.f6123/rr/674751.

14 Abramson JD, Rosenberg H, Jewell N, Wright JM. Authors response to the Cochrane review authors. www.bmj.com/content/347/bmj.f6123/rr/678736.

15 Ray KK, Seshasai S, Erqou S, Sever P, Jukema W, Ford I, et al. Statins and all-cause mortality in high-risk primary prevention. Arch Intern Med 2010;170:1024-31.

16 Cholesterol Treatment Trialists' (CTT) Collaboration. Lack of effect of lowering LDLcholesterol on cancer: meta-analysis of individual data from 175,000 people in 27randomised trials of statin therapy. PLoS One 2012;7:e29849.

17 Armitage J. The safety of statins in clinical practice. Lancet 2007;370:1781-90.

18 Golomb B, Evans M, Dimsdale J, White H. Effects of statin on energy and fatigue and exertion: results from a randomised controlled trial. Arch Intern Med 2012;172:1180-2.

19 Wardle J, Armitage J, Collins R, Wallendszus K, Keech A, Lawson A. Randomised placebo controlled trial of effect on mood of lowering cholesterol concentration. BMJ 1996:313:75-8.

20 Perez AC, Jhund P, Preiss D, Kjekshus J, McMurray JJ. Effect of rosuvastatin on fatigue in patients with heart failure. J Am Coll Cardiol 2013;61:1121-2.

21 Golomb B, Evans M. Statin adverse effects: a review of the literature and evidence for a mitochondrial mechanism. Am J Cardiovasc Drugs 2008;8:373-418

22 Hippisley-Cox J, Coupland C. Unintended effects of statins in men and women in England and Wales: population based cohort study using the QResearch database. BMJ 2010;340:c2197.

23 Smeeth L, Douglas I, Hall AJ, Hubbard R, Evans S. Effect of statins on a wide range of health outcomes: a cohort study validated by comparison with randomized trials. Br J Clin Pharmacol 2009;67:99-109.

24 Beers MH, Berkow R, eds. The Merck manual of diagnosis and therapy . 2013. www. merck.com. 


\section{Tips for patients}

- You can reduce your chances of having a heart attack or stroke

- The common risk factors are smoking, high blood pressure, raised blood cholesterol (circulating fat in the bloodstream), and lack of exercise. All of these can be improved with beneficial results

- Consider checking your own risk and seeing what effect lifestyle changes could have on reducing your risk (see http://qintervention. org/). Decision making tools such as the Mayo Clinic's (http://statindecisionaid.mayoclinic.org/index.php/statin/index) and the Nationa Prescribing Centre's (www.npc.nhs.uk/therapeutics/cardio/cd_lipids/resources/pda_Lipids.pdf) may help you to weigh up the risks and benefits of taking statins

- Statins lower your cholesterol level and reduce your chances of having a heart attack or stroke

- There is no evidence that statins cause cancer or dementia or increase your risk of dying from other diseases

- Statins may increase your chance of developing diabetes, particularly if you are obese, physically inactive, and have a family history of diabetes. Even then, the benefits of taking statins outweigh the smaller risk of developing diabetes

- People with diabetes benefit from taking statins

- If you get muscle pains while taking a statin you should consult your GP, who may want to do a blood test and may reduce your statin dose or advise taking it on alternate days

- Statins are more effective if taken in the evening on going to bed

- Grapefruit juice should be completely avoided if you are taking simvastatin as it can worsen the side effects, but this is not such a problem with atorvastatin

- Statins have to be taken every day and for the foreseeable future - they won't work if you don't take them

- Some drugs must be avoided or used with caution when taking statin. Consult your GP before taking any other drugs with a statin 2010;376:1622-4

26 Mills EJ, Wu P, Chong G, Ghement I, Singh S, Akl EA. Efficacy and safety of statin treatment for cardiovascular disease: a network meta-analysis of 170,255 patients from 76 randomized trials. QJM 2011;104:109-24.

27 Preiss D, Seshasai SR, Welsh P, Murphy SA, Ho JE, Waters DD, et al. Risk of incident diabetes with intensive-dose compared with moderate-dose statin therapy: a meta-analysis. JAMA 2011;305:2556-64

28 Waters DD, Ho JE, DeMicco DA, Breazna A, Arsenault BJ, Wun CC, et al. Predictors of new-onset diabetes in patients treated with atorvastatin: results from 3 large randomized clinical trials. J Am Coll Cardiol 2011:57:1535-45.

29 McKinney JS, Kostis WJ. Statin therapy and the risk of intracerebral hemorrhage. a meta-analysis of 31 randomized controlled trials. Stroke 2012;43:2149-56.

30 Smeeth L, Hemingway $\mathrm{H}$. Improving vascular health: are pills the answer? BMJ 2012;344:e3802.

31 National Institute for Health and Care Evidence. Lipid modification: Cardiovascular risk assessment and the modification of blood lipids for the primary and secondary prevention of cardiovascular disease (Clinical guideline 67.) 2010. http://guidance.nice.org.uk/cg67.
32 Stone NJ, Robinson J, Lichtenstein AH, Bairey Merz CN, Lloyd-Jones DM, Blum CB, et al. $2013 \mathrm{ACC} / \mathrm{AHA}$ guideline on the treatment of blood cholesterol to reduce atherosclerotic cardiovascular risk in adults. J Am Coll Cardiol 2013. doi:10.1016/j.jacc.2013.11.002.

33 Food and Drugs Administration. FDA expands advice on statin risks. 2012. www.fda.gov/ ForConsumers/ConsumerUpdates/ucm293330.htm.

34 Medicines and Healthcare products Regulatory Agency. Statins: risk of hyperglycaemia and diabetes. Drug Safety Update 2012;5:A2. www.mhra.gov.uk/Safetyinformation/ DrugSafetyUpdate/CON140667.

35 Bellosta S, Paoletti R, Corsini A. Safety of statins: focus on clinical pharmacokinetics and drug interactions. Circulation 2004;109:III50-7.

36 Egan A, Colman E. Weighing the benefits of high-dose simvastatin against the risk of myopathy. N Engl J Med 2011;365:285-7.

Accepted: 08 January 2014

Cite this as: BMJ 2014;348:g280

(c) BMJ Publishing Group Ltd 2014 


\section{Table}

Table 1| Effects of statins on from trials in primary prevention ${ }^{6}$

\begin{tabular}{|c|c|c|c|c|}
\hline Clinical outcome & Relative risk $(95 \% \mathrm{Cl})$ & $\begin{array}{c}\text { Median control group } 10 \\
\text { year risk (\%) }\end{array}$ & $\begin{array}{c}\text { Absolute } 10 \text { year risk reduction } \\
\text { or increase (\%) }\end{array}$ & $\begin{array}{c}\text { Number needed to treat or harm } \\
\text { for } 5 \text { years }(95 \% \mathrm{Cl})\end{array}$ \\
\hline $\begin{array}{l}\text { Combined fatal and non-fatal } \\
\text { cardiovascular events }\end{array}$ & $0.73(0.67$ to 0.80$)$ & 15.05 & 4.06 (3.01 to 4.97$)$ & 49 (40 to 66$)$ \\
\hline $\begin{array}{l}\text { Combined fatal and non-fatal } \\
\text { stroke }\end{array}$ & 0.78 (0.68 to 0.89$)$ & 5.88 & $1.29(0.65$ to 1.88$)$ & 155 (106 to 309$)$ \\
\hline All cause mortality & $0.86(0.79$ to 0.94$)$ & 10.4 & 1.45 (0.62 to 2.18$)$ & 138 (92 to 321$)$ \\
\hline \multicolumn{5}{|c|}{ Unintended effects (numbers needed to harm) } \\
\hline Type 2 diabetes* & 1.09 (1.02 to 1.17$)$ & 11.25 & $0.98(0.23$ to 1.91$)$ & 198 (105 to 889$)$ \\
\hline
\end{tabular}




\section{Figure}

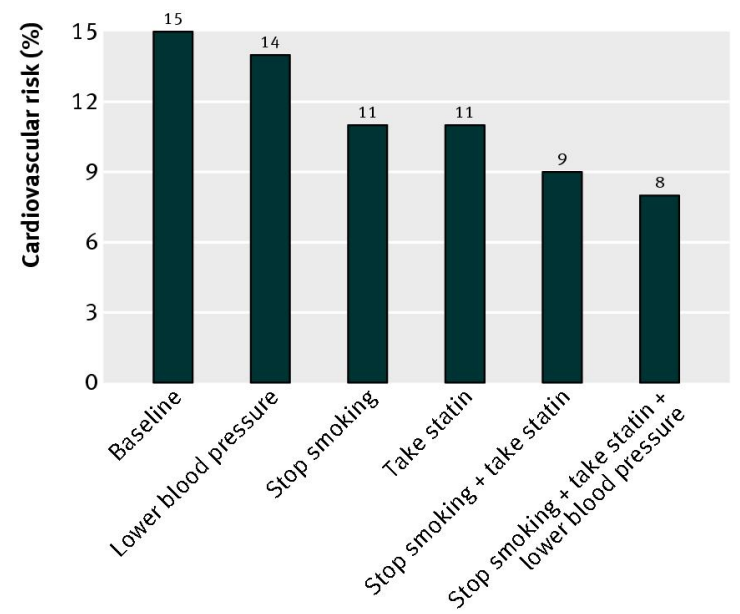

Predicted cardiovascular disease risk (percent) over 10 years for given characteristics based on QRISK Intervention software ${ }^{1}$ 